\title{
Paragenetic analysis of the upper mantle minerals from the heavy mineral concentrates of kimberlites based on an original statistic method.
}

Ananiev, V.A., Kuligin, S.S., Reimers, L.F., and Khlestov, V.V.

Institute of Mineralogy and Petrography of Siberian Branch of Russian Academy of Science, Novosibirsk, Russia.

At present the majority of researchers suppose, that mineral parageneses should form the basis of classification of the mantle rocks. In this case, the peculiarities of chemical composition of the rockforming minerals are the basic criteria of similarity of these rocks. The main aim of the proposed work is to find out the similarities or distinctions of deep-seated minerals from various parageneses by methods of mathematical statistics when solving the classification problems considering both the compositions of individual minerals and their paragenetic ratios in the typical polymineral associations.

The xenoliths of Udachnaya pipe are chosen as an object of exploration. Practically all types and varieties of mantle rocks are described among them (Ukhanov et al., 1988). There are also a series of varieties, found only in this kimberlite body. The data base on chemical composition of the main rock-forming minerals of mantle xenoliths from kimberlites (about 2000 samples), which includes the data on ortho- and clinopyroxene, garnet, olivine, chrome-spinellid and ilmenite has been created. In terms of mineralogy of lherzolites and eclogites, both literature data (Sobolev, 1974; Ukhanov et al., 1988; Spetsius, Serenko, 1990; Solov'eva et al., 1994) and a great number of our new materials were used.

To divide the obtained sampling into certain valuable groups with the significant variations in their parameters, a computer program allowing us to analyze the structures of multidimensional distribution with separation of clusters (concentration of points) on the chosen factor projections or in the multidimensional space of signs has been used. This program gives a possibility to solve the problems of similarity distinction for multidimensional massifs, with the help of the most significant criteria, which use the comparison of distributions for the discriminant function, calculated according to the formulated couple of groups. The present program is performed on the base of special

Figure 1.

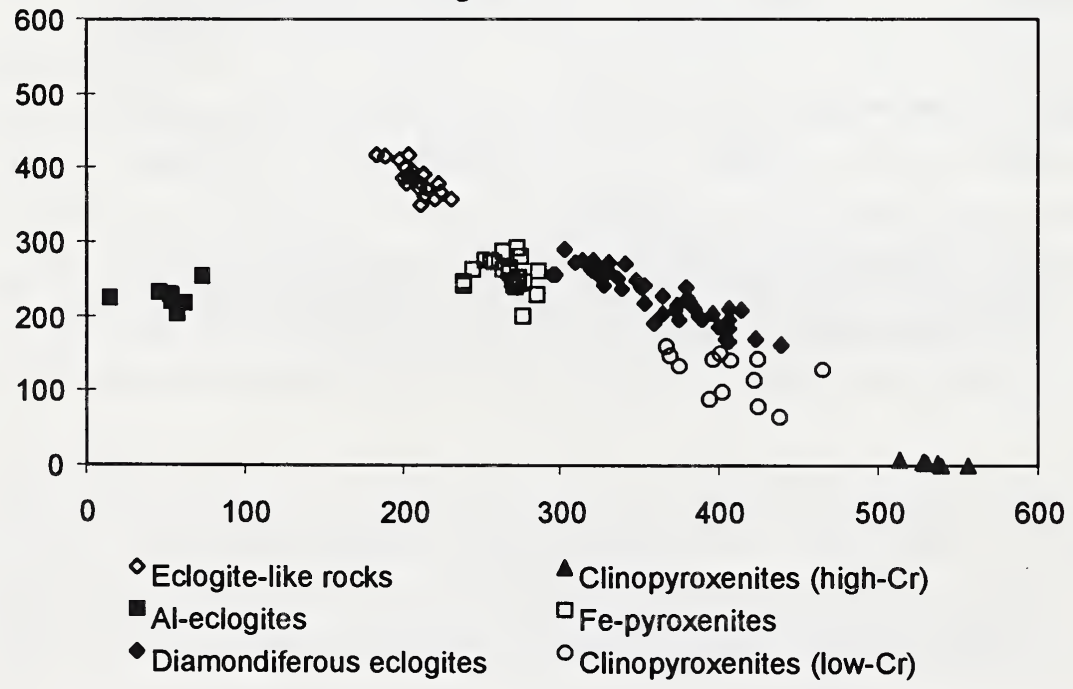


algorithm. Thus, an approximation of multidimensional distribution by Rosenblat-Parzen method followed by the extraction of the zone of every mode of the obtained distribution as an independent cluster, forms the basis of factor, cluster, regressive and discriminant procedures. In this case, a metrics of multidimensional space of describing signs (i.e. their scale) is transformed to minimize the entropy of approximated distribution within such linear transformations of coordinates, which provide the invariability of the value for all hypervolumes. The use of entropy as a criteria when choosing the metrics, eliminates the problem of scale correlations for the values of different type (for example, such as dimensions, masses, frequencies, etc.), giving, in fact, the dimensionless type of the table. In this transformed space the factor axes are defined according to the method of main components and have nonparametric dimensions, and clustering is performed by stages: first, the zone of every distribution mode is isolated as an individual cluster, and then the clusters, separated by the shallow "saddles" are united.

Some results of the cluster analysis, obtained with the help of the program, described earlier, are illustrated in the Figure 1. The application of the created method for the division of the sampling of chemically similar garnets from eclogites of different types, including the diamondiferous ones, eclogite-like rocks and pyroxenites is shown. In this case, the most part of data (about $70 \%$ ) divided into practically "pure" classes, corresponding to the eclogite-like rocks, aluminiferous eclogites, diamondiferous eclogites and three types of pyroxenites.

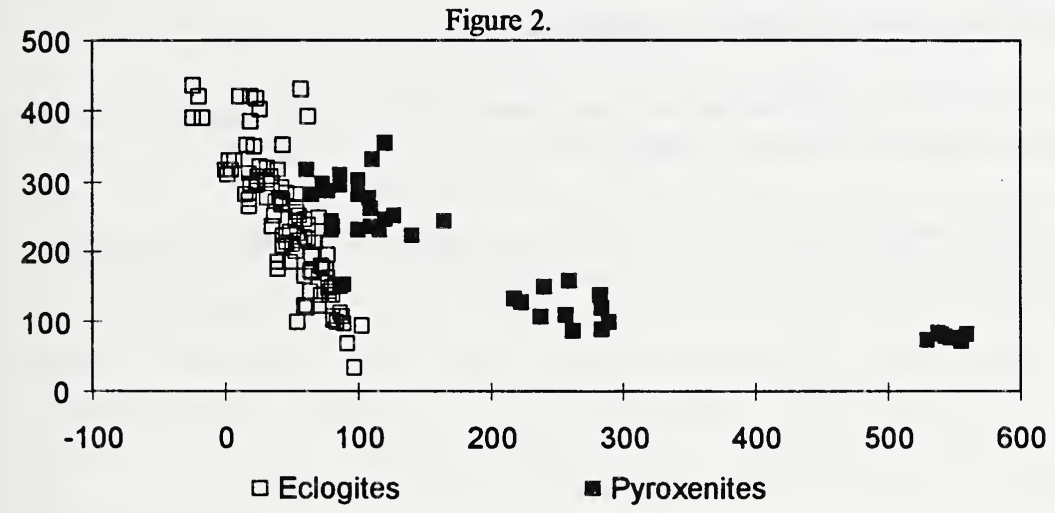

In Figure 2, the garnets are subdivided into certain samplings according to their paragenesis and the comparative analysis is performed. Presented projection shows the major distinction of garnets, according to their parageneses. In either case the coordinate axes correspond to the certain linear combinations of mineral components.

The performed calculations allowed to form an expert system to solve the problems of similarity/distinction of deepseated minerals, comparing observation multi-dimensional data with standard polygenetic groups of minerals, according to the following scheme. Every standard Q is a representative empirical sampling from $\mathrm{N}$...K- dimensional quantitative data (with $\mathrm{N}-\mathrm{K}^{2} \geq 100$ ), for which the statistical evaluations with the error not exceeding $1 \%$ are possible. The functions of $f_{q}(\mathbf{x})$ distributions, the relative $\mathrm{W}_{\mathrm{q}}$ statistic weights, proportional to the frequency of occurring of objects of particular type (there and further $q=1,2, . ., \mathrm{Q}$; and $\mathrm{x}$ - K-dimensional observation vector) are known for every standard. Thus $Q$ values for $f_{q}\left(\mathbf{x}_{*}\right)$, and corresponding $Q$ "features" $\tau_{q}\left(\mathbf{x}_{*}\right)$, characterizing the integral probability of observations with $f(x) \leq f\left(\mathbf{x}_{*}\right)$, may both be calculated for any new concrete observation $\mathbf{x}_{*}$. Then, for the sample with $\mathbf{x}=\mathbf{x}_{*}$, the probabilities of its reference to one or another standard class are related as the $\mathrm{W}_{\mathbf{q}} \tau_{\mathbf{q}}\left(\mathbf{x}_{*}\right)$ values, which can be calculated. But if every $\tau_{\mathbf{q}}\left(\mathbf{x}_{*}\right)$ is 
below any certain minimum critical level (which is 0.01 or another chosen limit), then the sample doesn't correspond any of the standards. This scheme provides correct probable estimations in all cases regardless of the number of standards, including the examples with partial overlapping of multidimensional standard areas, and at any form of isolating borders, when the application of the traditional linear procedures of factor or discriminant analysis gives no effect.

Thus, the performed explorations allow to solve the classificational and, as follows, the genetic problems of the deep-seated xenoliths of kimberlites statistically correctly on the basis of peculiarities of chemical composition of rock-forming minerals, and also to perform the calibration of the most wide-spread minerals of kimberlite concentrate, according to their paragenesis. As an example the minerals from Udachnaya kimberlite pipe concentrate (over 300 samples) have been used to clarify their paragenesis by specially adapted computer program.

\section{References}

Sobolev, N.V., 1974, Deep-seated inclusions in kimberlites and the problem of the Upper Mantle composition: Novosibirsk, Nauka, $263 \mathrm{p}$.

Solov'eva, L.V., and Vladimirov, B.M., et al., 1994, Kimberlites and kimberlite-like rocks: the Upper Mantle substance under ancient Platforms: Novosibirsk, Nauka, 256 p.

Spetsius, Z.V., and Serenko, V.P., 1990, Composition of continental Upper Mantle and lowermost strata of the crust under Siberian Platform.: Moscow, Nauka, 272 p.

Ukhanov, A.V., Pyabchikov, I.D., and Kharkiv, A.D., 1988, Lithospheric Mantle of Yakutian kimberlite province: Moscow, Nauka, 28 p. 